J-ABDIPAMAS (Jurnal Pengabdian Kepada Masyarakat)

Vol. $4 \bullet$ No. $1 \bullet 2020$

ISSN : 2581-1320 (Print) ISSN : 2581-2572 (Online)

Homepage: http://ejurnal.ikippgribojonegoro.ac.id/index.php/J-ABDIPAMAS

\title{
PEMANFAATAN APLIKASI CASHBACK DALAM BERBELANJA ONLINE
}

\author{
Perani Rosyani ${ }^{1}$, Devi Yunita ${ }^{2}$, Intan Kumala Sari ${ }^{3}$, Muhammad Rosdiana $^{4}$, Koirunnisya ${ }^{5}$ \\ ${ }^{1}$ Universitas Pamulang. Email: dosen00837@unpam.ac.id \\ 2Universitas Pamulang. Email: dosen00846@unpam.ac.id \\ 3Universitas Pamulang. Email: dosen02368@unpam.ac.id \\ ${ }^{4}$ Universitas Pamulang. Email: dosen02354@unpam.ac.id \\ 5Universitas Pamulang. Email: dosen02386@unpam.ac.id
}

\begin{abstract}
The trend of online shopping for several years is very attractive to users, especially mothers who are already busy with their daily routines. Over time the increase in e-commerce companies also increased products issued to attract custumer's interest to shop online. One of them is the cashback obtained after shopping at several cooperating marketplaces. This is the purpose of our PKM to educate the public so that they understand the use of more benefits from supporting applications for this marketplace. In this PKM we explain the proven Shopback application that can generate other benefits after shopping. This can increase profits and knowledge for mothers who love to shop online. The results of this PKM is after this socialization mothers can implement this application every day in supporting transactions online to get savings from their shopping.
\end{abstract}

Keywords: cashback, e-commerce, online shop

\begin{abstract}
ABSTRAK
Tren belanja online beberapa tahun ini sangat diminati oleh para pengguna khususnya ibu-ibu yang sudah sibuk dengan rutinitas sehari-hari. Seiring waktu bertambahnya perusahaan e-commerce bertambah juga produk-produk yang dikeluarkan untuk menarik minat custumer untuk berbelanja online. Salah satunya adalah cashback yang didapat setelah belanja di beberapa marketplace yang bekerja sama. Hal ini yang menjadi tujuan PKM kami untuk meng-edukasi masyarakat agar paham penggunaan manfaat lebih dari aplikasi pendukung marketplace ini. Dalam PKM ini kami menjelaskan mengenai aplikasi Shopback yang sudah teruji dapat menghasilkan keuntungan lain setelah belanja. Hal ini dapat menambah keuntungan dan pengetahuan bagi ibu-ibu yang senang berbelanja online. Hasil PKM ini adalah setelah adanya sosialisasi ini ibu-ibu dapat menerapkan dalam sehari-hari aplikasi pendukung ini dalam bertransaksi online untuk mendapatkan tabungan dari hasil belanja mereka.
\end{abstract}

Kata Kunci: cashback, e-commerce, toko online

\section{PENDAHULUAN}

Berbagai e-commerce di era digital saat ini terus berkembang seperti shoppe, tokopedia, bukalapak, Lazada, carousel, jd.id ,dll. Berbagai promosi yang menggiurkan kerap di sodorkan, hal ini membuat masyarakat melirik pasar online sebagai media untuk memenuhi kebutuhan primer hingga tersier mereka. Selain harga yang jauh lebih murah dibandingkan toko offline kemudahan yang di berikan oleh e-commerce tersebut adanya free ongkir yang di berikan serta fitur-fitur yang menarik (Kasus, Gunung, \& Kabupaten, n.d.). Sehingga masyarakat sangat dimanjakan tidak perlu repot pergi jauh- 
jauh keluar rumah untuk membuang waktu dan dimanjakan dengan teknologi yang ada.(Saragih \& Ramdhany, 2013)

Seiring dengan perkembangan teknologi banyak perusahaan e-commerce menawarkan beragam aplikasi tambahan yang menguntungkan bagi custumer dalam berbelanja online. Benefit yang di tawarkan sangat menarik selain adanya free ongkir dan potongan belanja (Putra, Kumadji, \& Yulianto, 2016) berupa voucher, saat ini ada aplikasi-aplikasi pendukung belanja di e-commerce yang memberikan cashback setelah kita berbelanja sehingga menarik minat custumer untuk berbelanja. Di era digital memang akan lebih tepat melakukan promosi mengunakan media digital.(Selatan, 2018)

Cashback ini sangat menarik jika masyarakat tau, karena tidak hanya dapat untuk membeli produk lain di beberapa e-commerce tetapi bisa di uangkan kembali. Sehingga hal ini sangat menarik jika masyarakat paham cara penggunaannya. Di samping sebagai deposit di saat kita butuh, dan juga dapat di cairkan sebagai dana tambahan untuk dapat dibelanjakan kembali. Aplikasi cashback ini salah satunya adalah "Shopback". Aplikasi yang berasa didalam platform android ini sudah terbukti dapat mencairkan uang yang sudah kita belanjakan di beberapa e-commerce. E-commerce yang sudah bekerja sama dengan aplikasi ini cukup beragam, baik dari online shop, hotel, hingga tiket pesawat.

Aplikasi ini berkerja sebagai perantara untuk ke aplikasi e-commerce yang di tuju. Kita hanya cukup membuka aplikasi "shopback" ini kemudian memilih e-commerce yang kita tuju. Dan aplikasi ini akan menuntun ke aplikasi e-commerce pilihan kita. "Shopback" tidak merubah tampilan apapun dari e-commerce yang kita buka. Aplikasi ini jelas hanya perantara dengan aplikasi yang akan kita tuju. Melalui aplikasi ini kita akan melakukan cekout barang lalu menyelesaikan pembayarannya. Pada saat kita sudah selesai melakukan pembayaran, maka aplikasi cashback ini akan memberikan notifikasi besaran cashback yang didapat. Besaran cashback yang di dapat dari e-commerce yang ada berbeda-beda. Tergantung kerja sama di antar e-commerce dan aplikasi shopback ini.

Dengan adanya benefit-benefit yang ditawarkan maka kami dari universitas pamulang dalam rangka menjalankan Tri Dharma Perguruan tinggi melakukan sosialisasi kepada masyarakat agar dapat memanfaatkan benefit yang ada. Karena tidak semua masyarakat paham cara menggunakannya. Dengan adanya kegiatan ini diharapkan dapat meningkatkan knowledge ibu-ibu dalam berbelanja online didalam $e$ commerce.

Persiapan yang dilakukan agar kegiatan ini berjalan dengan lancar dimulai dari menyusun materi pelatihan, mempersiapkan peralatan dan perlengkapan pendukung yang dibutuhkan selama kegiatan berlangsung. Materi yang dipersiapkan disesuaikan dengan praktik yang akan dilakukan selama kegiatan dengan tujuan agar materi dapat dengan mudah di pahami oleh para peserta kegiatan.

\section{METODE PELAKSANAAN}

Bentuk kegiatan yang akan dilaksanakan dalam Pengabdian Kepada Masyarakat pada Ibu rumah tangga adalah Pengenalan dan pengelolaan dalam aplikasi online shop berbasis mobile untuk membantu Ibu rumah tangga dalam memanfaatkan Aplikasi 
Online shop. Metode yang digunakan dalam kegiatan ini meliputi pelatihan dan praktik dalam dengan menggunakan slide yang tersedia, ceramah dan tanya jawab. Diakhir pemberian maeri peserta diberikan kesempatan untuk bertanya mengenai materi ang telah disampaikan.

Adapun langkah-langkah dalam kegiatan ini yaitu: dengan memberikan materi tentang pemahaman penggunaan aplikasi untuk mendapatkan cashback tambahan ddidalam berbelanja online dengan melakukan presentasi, menggunakan media LCD proyektor sehingga dapat dilihat dan dimengerti oleh peserta. Membagi peserta untuk diberi kesempatan mencoba menggunakan Aplikasi Cashback dan bertanya sehingga apa yang dijelaskan oleh Tim Pengabdian dapat dipahami dengan baik. Mendampingi para peserta untuk menginstal aplikasi tambahan, dan mengajarkan step by step penggunaan aplikasi online shop untuk mendapatkan cashback tambahan.

\section{HASIL DAN PEMBAHASAN}

Kegiatan pengabdian masyarakat ini dilaksanakan satu kali dalam satu semester. Kegiatan ini dilaksanankan pada tanggal 9,10, dan 11 May 2018. Peserta pengabdian masyarakat ini berjumlah 15 orang. Tujuan dari kegiatan ini adalah untuk melakukan sosialisasi pemanfaatan aplikasi tambahan guna mendapatkan keuntungan didalam berbelanja online.

Kegiatan ini dimulai dari pukul 08.00 sampai pukul 14.00. Kegiatan ini dilaksanakan disalah satu rumah warga didaerah kutabumi Tangerang. Penyampaian materi oleh Perani Rosyani, M.Kom. Adapun materi yang disampaikan tentang simulasi untuk mendapatkan cashback di dalam berbelanja online.

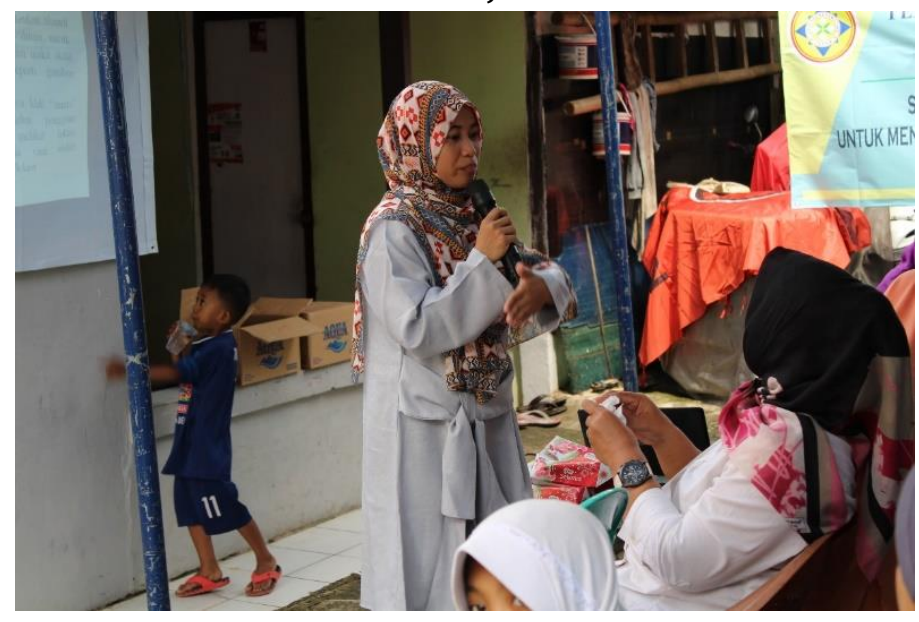

Gambar 1. Penjelasan teknis untuk Pemberian materi

Pada gambar 1. Materi telah disampaikan dan melakukan tanya jawab kepada peserta. Untuk menguji sejauh mana tingkat pemahaman peserta didalam penjelasan yang sudah disampaikan pemateri. 


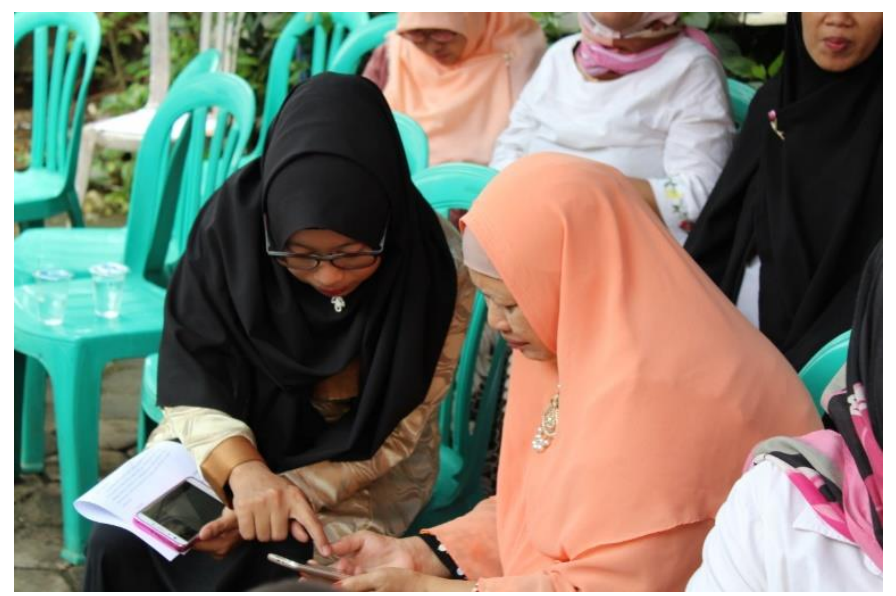

Gambar 2. Pendampingan untuk menggunakan aplikasi Online Shop

Kegiatan selanjutnya adalah pendampingan untuk melakukan praktik untuk melakukan langkah-langkah mendapatkan cashback tambahan dalam berbelanja online. Aplikasi yang diinstal antara lain adalah "Shopback" karena lebih praktis untuk mendapatkan cashback, karena aplikasi tersebut sudah bekerja sama dengan perusahan-perusahan e-commerce yang ada diindonesia. Diantaranya Tokopedia, shoppe, bukalapak, JD.ID dan lain-lain.

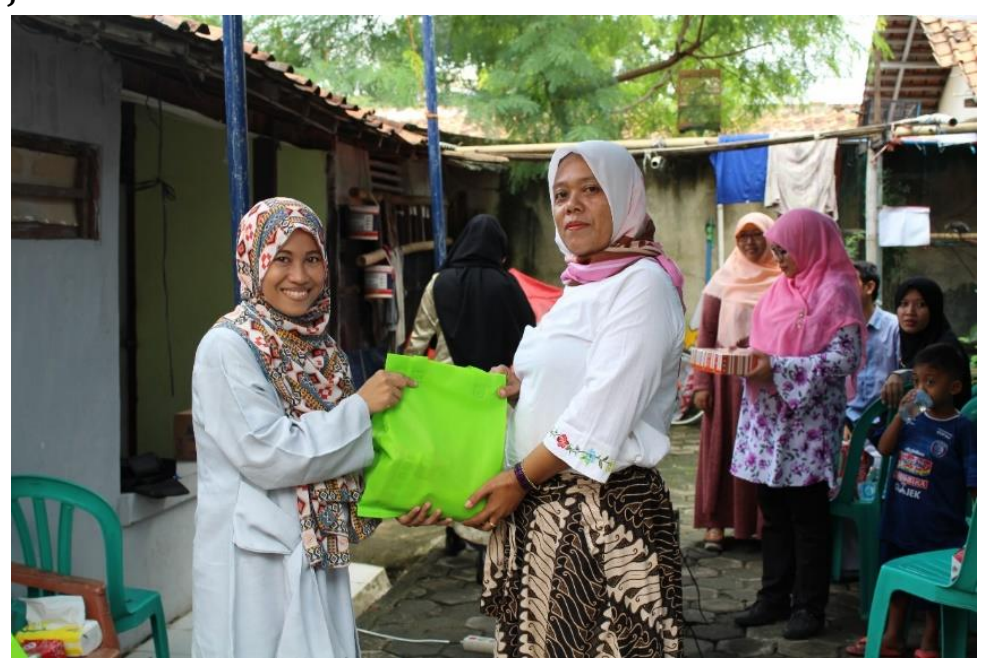

Gambar 3. Pemberian bingkisan sebagai ucapan terima kasih kepada Ibu RT

Hasil didalam kegiatan ini peserta mampu memahami dan mengimplementasikan materi yang diberikan. 3 dari 15 peserta sudah berhasil melakukan belanja online dengan mendapatkan cashback tambahan. Cashback yang diberikan tidak dapat di klaim langsung harus menunggu sekitar 30 hari, dan cashback ini dapat diakumulasi sebagai tabungan untuk para peserta.

\section{SIMPULAN}

Dengan adanya kegiatan ini kami berharap akan lebih memberikan pemahaman yang lebih kepada ibu-ibu rumah tangga di sekitar daerah kecamatan kutabaru khususnya, agar dapat memaksimalkan teknologi yang ada. Serta memanfaatkan aplikasi-aplikasi yang mempunyai nilai tambah untuk income ibu-ibu 


\section{UCAPAN TERIMA KASIH(Jika diperlukan)}

Terima Kasih kepada LPPM Universitas Pamulang dan Prodi Teknik Informatika yang telah mensupport kegiatan Pengabdian Kepada Masyarakat ini.

\section{DAFTAR RUJUKAN}

Kasus, S., Gunung, K., \& Kabupaten, S. (n.d.). JAMAIKA : Jurnal Abdi Masyarakat, 83-96.

Putra, E., Kumadji, S., \& Yulianto, E. (2016). PENGARUH DISKON TERHADAP MINAT BELI SERTA DAMPAKNYA PADA KEPUTUSAN PEMBELIAN (Study pada konsumen yang membeli produk diskon di Matahari Department Store Pasar Besar Malang). Jurnal Administrasi Bisnis S1 Universitas Brawijaya, 38(2), 184-193.

Saragih, H., \& Ramdhany, R. (2013). Pengaruh Intensi Pelanggan Dalam Berbelanja Online Kembali Melalui Media Teknologi Informasi Forum Jual Beli (Fjb) Kaskus. Jurnal Sistem Informasi, 8(2), 100. https://doi.org/10.21609/jsi.v8i2.331

Selatan, C. (2018). PELATIHAN PEMANFAATAN MEDIA SOSIAL SEBAGAI MEDIA PROMOSI ONLINE UNTUK PELAKU UMKM DI CILACAP Andi Dwi Riyanto ${ }^{1}$, Muhammad Faiz Noeris 2 1STMIK AMIKOM Purwokerto . Email: andi@amikompurwokerto.ac.id media digital dalam melakukan promosi . Berdasarkan data, 2(2), 53-58. 
36 J-Abdipamas, Vol. 4, No. 1 April, 2020 